\title{
Rüzgâr Enerji Santrali Projelerinde Topografik Yersel Ölçme ve Gözlemlerden Kaynaklanan Risklerinin İncelenmesi
}

\author{
Eray CAN ${ }^{1}$, Hikmet ERBIYIK ${ }^{2}$ \\ ${ }^{1}$ Yalova Üniversitesi, Mühendislik Fakültesi, Ulaştırma Mühendisliği Bölümü, Yalova / Türkiye. \\ ${ }^{2}$ Yalova Üniversitesi, Mühendislik Fakültesi, Endüstri Mühendisliği Bölümü, Yalova / Türkiye.
}
Sorumlu yazar ${ }^{1}$ e-posta: can.eray@hotmail.comＯRCID ID: http://orcid.org/0000-0002-8192-1703
2e-posta: hikmeterbiyik53@gmail.com ORCID ID: http://orcid.org/0000-0001-8010-0199

\begin{tabular}{|c|c|}
\hline Geliş Tarihi: 25.12.2019 & $\begin{array}{l}\text { Kabul Tarihi: } 20.08 .2020 \\
\text { Öz }\end{array}$ \\
\hline $\begin{array}{c}\text { Anahtar kelimeler } \\
\text { Rüzgâr enerji } \\
\text { santralleri; } \\
\text { Mühendislik ölçmeleri; } \\
\text { Hata Türü etkileri } \\
\text { analizi (HTEA); Pareto } \\
\text { analizi; Risk belirleme }\end{array}$ & $\begin{array}{l}\text { Günümüzde ülkelerin toplumsal refahlarının artması ve diğer ülkelerle ileri düzeyde rekabet } \\
\text { edebilmelerinde, enerjinin payı oldukça büyüktür. Özellikle son yıllarda, toplumlardaki nüfus artışları ve } \\
\text { bu nüfus artışları sonucu; kentleşmenin, sanayileşmenin ve savunmanın öneminin artması, enerji } \\
\text { ihtiyacını her geçen gün daha da artırmaktadır. Yine insanoğlu çağımızda; fosil yakıtların çevreye vermiş } \\
\text { oldukları zararlarının bulunması, bu yakıt türünün hızla tükenmeye başlaması ve bu yakıt türlerinin } \\
\text { maliyetlerinin yüksek olması vb. sebeplerle alternatif enerji kaynaklarına yönelmektedir. Özellikle enerji } \\
\text { türlerinin arasında büyük bir paya sahip olan sürdürülebilir elektrik enerjisi üretiminde, fosil yakıtlar } \\
\text { yerine, rüzgâr enerjisinden faydalanmak, alternatif enerji kaynaklarının başında gelmektedir. Rüzgâr } \\
\text { enerjisi kullanarak elektrik üreten santral projelerinin tasarımında uygulanmasında ve işletilmesinde, } \\
\text { projenin tasarlandığı arazinin, projeyle uyumu da önemli bir unsur olmaktadır. Bu uyumun } \\
\text { gerçekleşebilmesi için de arazide yapılan mühendislik ölçmeleri son derece önemli olmaktadır. } \\
\text { Çalışmada, bu enerji santrallerin tesis edilebilmesi için yapılan mühendislik ölçmeleri sırasında oluşan } \\
\text { risk ve hata faktörleri, Hata türü etkileri analizi adı verilen (HTEA) sistematiği içinde araştırılmıştır. Ayrıca } \\
\text { belirlenen bu risklerin önem sırası da, Pareto analizi sistematiğinde belirtilmiştir. Yine, karşılaşılabilecek } \\
\text { olan bu risklere karşı alınabilecek önlemler, uzman görüşleri dikkate alınarak incelenmiştir. }\end{array}$ \\
\hline
\end{tabular}

\section{Research of the Risks that are Originated from Topographic Terrestrial Observations in Wind Energy Power Plant Projects}

\footnotetext{
Keywords

Wind energy power plants; Engineering measurements; Failure mode effect analysis

(FMEA); Pareto analysis; Risk detection
}

\begin{abstract}
In our days, in order to increase the social prosperity of the nations and gaining competitive advantage against the other nations, the share of the energy is prominent. Nowadays the increase of populations in the nations and as a result of this situation; the increase of urbanization, industrialization and defence needs, are increasing the energy demand. Again, the human is being forwarded to the alternative energy sources, due to increase of fossil fuel damages into environment, depletion of fossil fuels in a speedy manner and increase of the cost of the fossil fuels, etc. Especially, in the production of sustainable electrical energy, that has an important share among the other energy types; preferring wind energy instead of fossil fuels is consisting of the leading alternative energy sources. In design, implementation and operation of the electrical power plants projects that utilize wind energy, the conformity of the concerned field with the project becoming an important factor. In order to realize this conformity, the engineering measurements that are made in the relevant field are also becoming important. In this study, the failure factors that occurred during the engineering measurements for the establishment of these power plants were examined in the FMEA systematic called Failure Mode Effects Analysis. However, the order of importance of these identified risks is indicated in the Pareto analysis. Beside the preventions that can be taken against these risks are examined by taking into consideration the expert opinions.
\end{abstract}




\section{Giriş}

Son yıllarda özellikle, teknolojik gelişmeler ve dünyadaki metropollerin de büyümesiyle birlikte, fosil yakıtların tüketiminde büyük oranda artışlar olmaktadır. Kullanılan bu fosil yakıtların; çevreye zarar vermesi, yeraltı ve yerüstü madencilik faaliyetleriyle yüksek maliyet gerektiren çalışmalar sonucu üretilmiş olmaları, artan nüfusla birlikte hızla tükeniyor olması insanoğlunu alternatif enerji kaynakları arayışına yöneltmiştir. Bu arayış sonucunda da pahalı, çevreye zararlı ve tükenmeye başlayan fosil yakıtlarının yerine daha uygun maliyetli, sürdürülebilir ve çevreyle uyum içindeki rüzgâr, su, jeotermal ve güneş ışığı gibi alternatif enerji kaynaklarına odaklanılmıştır. Özellikle çağımızda kentlerdeki yaşam kalitesin de artmasıyla elektrik enerjisine olan talep daha da artmaktadır. Artan bu enerji türünün karşılanmasında ve üretilmesinde, tükenmeye başlayan fosil yakıtlar artık yerini alternatif ekonomik, yenilenebilir ve çevresel bir enerji kaynağı olan rüzgâr enerjisine bırakmaktadır. (Şen 1999; Tarawneh and Şahin 2003; Ramachandra and Shruthi, 2005; Cellura et al. 2008; Ajayi 2009; Beccali et al. 2010; Amoo, 2012; Miryousefi et al. 2016; Marugána et al. 2018). Rüzgâr enerjisi kullanarak elektrik üreten santral projelerinin (Rüzgâr enerjisi santralleri) tercih edilmesiyle ilgili olarak;

- Yatırım maliyetleri açısından incelendiğinde diğer alternatif enerji kaynaklarına nazaran düşük maliyetlere sahip olması

- Projelendirme ve tesis edilme sürelerinin kısa olması

- Elektrik üretimi için tesis edilen rüzgâr enerji santrallerinin işletme kolaylıklarının bulunması,

- Rüzgâr enerjisi santrallerinin bakım-onarım faaliyetleri incelendiğinde maliyetlerinin düşük olması

- Dünyadaki ülkelerin bu santralleri kurmasıyla kaynak olarak dışa bağımlı olmamaları

- Rüzgâr enerjisinin doğal tükenmeyen ve gelecekte de temin edilebilecek bir enerji olması,
- Rüzgâr enerjisinin atmosferik ısınmaya yol açmayan, $\mathrm{CO}_{2}$ emisyonu olmayan, insan sağlığına zarar vermeyip, çevreyle uyumlu olması,

- Elektrik enerjisi üretmek üzere tasarlanan rüzgâr enerji santrallerinin teknolojik gelişmelere açık olması

gibi sebepler sayılabilmektedir. Böylesine avantajları oldukça fazla sayılabilecek rüzgâr enerji santralleri projelerinin, tasarımı tesisi ve işletilmesi sırasında, tesis edileceği arazinin konumu, geometrisi, sayısal yüksek modelleri, eğim koşulları, jeolojik ve jeofiziksel koşulları da önemli olmaktadır. Ayrıca rüzgâr enerji santrali projesinin, arazinin yükseklik modeliyle uyumu da rüzgâr enerjisi ve hızından maksimum seviyede yararlanılmasında üzerinde durulması gereken önemli bir konu olmaktadır (Şen 1999). Arazinin sayılan bu özelliklerinin doğru ve güncel bir şekilde yansıtılması ve rüzgâr enerjisi santral projelerine altlık olarak hizmet verecek harita plan ve kesitlerin de hassas olarak üretilmesi için de arazide yapılacak olan hassas mühendislik ölçüm çalışmalarının önemini daha da arttırmaktadır. Rüzgar enerji santralleri projelerine altlık olacak haritalar için yapılacak olan yatay ve düşey konum ölçümlerinde, arazide çok hassas olarak tesis edilmiş, optimizasyon ve istatistiki testleri yapılmış ve koordinatları hassas olarak bilinen yer kontrol ölçme ağına ihtiyaç duyulmaktadır. Bu ağda yapılan yatay konum belirleme ile hesaplama için $\mathrm{mm}$ hassasiyetindeki Global Positioning Systems (GPS) ölçmeleri ve düşey konum belirleme ile hesaplamaları için ise yine $\mathrm{mm}$ hassasiyetindeki dijital nivo kullanılarak geometrik nivelman ölçümleri, arazinin topografik ve eğim durumunu yansitan harita, plan ve kesitlerin üretilmesinde önemli roller oynamaktadırlar. Özellikle günümüzde kullanılan Lidar uygulamaları, arazinin güncel durumunun hassas olarak yansıtılması için kullanılan yöntemler arasında yerini almıştır. (Shu et al. 2016; Li and Yu 2017; Fang et al. 2018). Rüzgar enerji santralleri aracılığıyla elektrik enerjisi üretimini amaçlayan projelerde, karşılaşılan risklerin belirlenmesi ve gerekli önlemlerin 
alınmasına yönelik, güncel bir çok risk analizi ve risk yönetimi çalışmaları literatürde yapıldı̆̆ı görülmektedir. Konu ile ilgili olarak literatürde çalışılan risk yönetimi ve risk analizi yöntemleri arasında; Hata Ağacı Analizleri (Kang et al. 2019; Brouwer et al. 2018), Ağırlıklı Toplam Yöntemi (WSM) (Kucukali, 2016), SWOT (Güçlü, zayıf, fırsat ve tehdit analizleri and McKinsey Matris Analizleri (Rolik 2017), AHP (Analitik Hiyerarşi Prosesi analizi), (Xinyao et al. 2017), Correlation-FMEA (Korelasyon Hata Türü Etkileri Analizi) (Kang et al. 2017), Hata Türü Etkileri Analizi ve diğer risk metotları (Leimeister and Kolios 2018; Yssaad and Abene 2015) gibi risk analizleri sayılabilmektedir. Elektrik enerjisinin üretilebilmesi için, rüzgar enerji santrallerinin kurulacağı topografyanın güncel ile hassas durumunun belirlenmesi ve bununla birlikte bu topografyaya ait sayısal yükseklik modelinin (Digital Elevation Model) (DEM) oluşturulması ve analiz edilmesi oldukça önemli bir konu olmaktadır. Bu konu ile ilgili literatürde güncel olarak önemli çalışmalar yapılmıştır. (Argin et al. 2019; Han et al. 2018; Kim and Lim 2017; Gualtieri 2019; Bosch et. al 2018; Liua et al. 2019; Nedjari et al. 2017; Lun et al. 2007; Ferragut 2010; Beccali et al. 2010). Yine Rüzgar enerji santralleri aracılığıyla elektrik enerjisi üretimini amaçlayan projelerde topografyanın güncel olarak haritasının yapılmasında ve topografyaya ait sağ lıklı, hassas ve proje ile uyumlu bir sayısal yükseklik modelinin (SYM) oluşturulmasında arazide gerçekleştirilen mühendislik ölçmelerinin payı da oldukça büyük olmaktadır. (Fang at al. 2018; Shu et al. 2016; Li and Yu 2017; Finardi et al. 1998). HTEA ve Pareto yöntemleri, risk belirleme yöntemleri arasında yer alan ve risklerin önceden belirlenip önlemlerinin alınması ve öncelik sırasına göre sıralanmasına yardımcı olan yöntemler olup yine literatürde oldukça yaygın kullanım alanına sahiptir. Bununla birlikte rüzgar enerjisine yönelik çeşitli alanlarda uygulanmaktadır. (Shafiee and Dinmohammadi 2014; Tazi et al. 2017). Bu çalışmada ise elektrik enerjisi üretmek için kurulan rüzgâr enerji santralleri projelerinde;

- Risk analizi ve risk yönetimi
- Topografya ile uyum,

- Arazi ölçmeleri

- HTEA ile Pareto risk belirleme yöntemleri

olarak sayılabilecek 4 faktör bir arada incelenmektedir. Böylelikle bu tür projelerin tasarımı ve yapılması sırasında, topografya ile uyumun sağlıklı bir şekilde sağlanması için, gerçekleştirilen mühendislik ölçmelerin doğru yapılması gerektiği vurgulanmış ve burada oluşan riskler ve önlemler HTEA ve Pareto sistematiğinde araştırılmıştır. Bunun sonucu olarak da bu 4 faktörün beraber incelenmesi ve araştırılması ile birlikte literatüre yeni bir katkı yapılmaya çalışılmıştır.

\section{Metot: Hata Türü Etkileri Analizi (HTEA) ve Pareto Sistemi}

Literatürde de yaygın olarak kullanılan bu yöntem, gerek projelerde gerekse de kullanılan sistemlerde başarısızlıkların ve risklerin zarar vermeden önce keşfedilmesi ve saptanan bu hataların önüne geçilmesi ve önlemlerin bir an önce alınması için kullanılan bir sistematik metot olarak karşımıza çıkmaktadır. (Liu et al. 2013; Akın 1998). Bahsetmiş olduğumuz bu yöntem, proje, sistem ve planlamalarda, risk ve hataları belirlerken ilgili yönetmelik,tüzük ve düzenlemeleri de dikkate almaktadır. Bunun sonucu olarak da bu yöntem diğer risk belirleme sistematiklerinden belirgin bir şekilde de ayrılmaktadır. Bu analiz oldukça yaygın bir uygulama alanında kullanılmakla birlikte hataların belirlenmesi için oldukça sistematik ve etkili bir metot olmaktadır. (Liu et al. 2013; Chin et al. 2009; Wang et al. 2009). Bu metodun, projenin ya da bir planlamanın ilk aşamasında ya da tasarımında uygulanması buralarda yapılacak olan önlemlerin alınmasında daha az maliyetlerin oluşmasına sebep olacaktır. Uygulanan bu metodun sağladığı avantajlar;

- Uygulanacak olan projenin ya da planlamanın kalitesini ve sağlamak

- Projede uygulanacak olan iş kalemlerinin öncelik sıralamasını gerçekleştirmek 
- Proje ya da planlanan faaliyetler için bütün uygulama boyunca riskleri belirlemek ve bu risklerin etkilerini belirlemek

- Projedeki hataların ve yanlışlıkların önüne geçilmesini sağlamak ve bunların belirlenmesi için sistematiğin kurulmasına yardımcı olmak

- Risklere karşı belirlenebilecek önlemlerin alınmasını sağlamak

- Hataların izlenmesini ve dokümantasyonlarının yapılmasını sağlamak

vb. gibi sıralanabilmektedir. Bu risk belirleme sistematiğinde her bir belirlenen risk ve sistem için hangi ekibin görev alacağının belirlenmesi de önemli olmaktadır. Belirlenen bu ekibin bilgi ve tecrübesi ışığında RÖS yani risk öncelik sayısı hesaplanmaktadır. Projelerde ya da sistemlerde kullanılan bu yöntemin (HTEA) uygulanması sırasında risklerin belirlenmesi için belirli bir formül ve sistematik izlenmektedir. Sonuç olarak projelerde risklerin ve yanlışııların önceliklerini saptamak için üç unsur dikkate alınmaktadır. Bunlar;

- Hatanın oluşma olasılığı,

- Hatanın şiddeti,

- Hatanın saptanabilirliliği

üzerinden olmaktadır. (Akın 1998; Wang et al. 2009; Xiao et al. 2011; Su et al. 2012). Bu etkenlerden hatanın oluşma olasılığı; riskin sıklığını; (1-10 puan arası puan sistemi kullanılmaktadır.) göstermektedir.(Çizelge 1).

Çizelge 1.Riskin Oluşma Olasılığı (O) Derecesi (Akın 1998; Xiao et al. 2011; Su et al. 2012)

\begin{tabular}{ccc}
\hline Riskin Meydana Gelme Sıklı̆̆ı & Hata Olasılık & Kademe \\
\hline Çok Yüksek. Kaçınılmaz risk & $1 / 2$ 'den fazla & On \\
\cline { 2 - 3 } & $1 / 3$ & Dokuz \\
\hline Yüksek. Tekrarlan risk & $1 / 8$ & Sekiz \\
\cline { 2 - 3 } & $1 / 20$ & Yedi \\
\cline { 2 - 3 } Orta. Bazen Olan risk & $1 / 80$ & Altı \\
\hline \multirow{2}{*}{ Düşük. Kısmen Olan risk } & $1 / 400$ & Beş \\
\cline { 2 - 3 } & $1 / 2000$ & Dört \\
\hline Pek az. Olası Görülmeyen risk & $1 / 15000$ & Üç \\
\cline { 2 - 3 } & $1 / 150000$ & İki \\
\hline
\end{tabular}

Hatanın şiddeti; zararı oluşturan durumun oranını (1-10 arasında yapılan puanlama sistemi kullanılır) (Çizelge 2). Riskin saptanabilirliliği ise zararı oluşturan durumun tespit edilmesindeki güçlük kademesini belirtmektedir. (1-10 arasında yapılan puanlama sistemi kullanılır) (Çizelge 3 ).

Çizelge 2. Riskin Şiddet Bileşeninin Derecelendirilmesi (A) (Akın 1998)

\begin{tabular}{ccc}
\hline $\begin{array}{c}\text { Etkilenme } \\
\text { Türü }\end{array}$ & Şiddetin Yansıması & Kademesi \\
\hline $\begin{array}{c}\text { Aniden Gelen } \\
\text { Yüksek tehlike }\end{array}$ & $\begin{array}{c}\text { Felakete neden olan ve aniden } \\
\text { gelen hata türü }\end{array}$ & On \\
\hline $\begin{array}{c}\text { Aniden Gelen } \\
\text { Tehlike }\end{array}$ & $\begin{array}{c}\text { Yüksek zarar verebilecek aniden } \\
\text { gelen hata türü }\end{array}$ & Dokuz \\
\hline Çok Yüksek & $\begin{array}{c}\text { Projenin çok fazla ve yüksek } \\
\text { derecede zarar görmesini sağlayan } \\
\text { yıkıcı etkiye sahip hata türü }\end{array}$ & Sekiz \\
\hline Yüksek & $\begin{array}{c}\text { Ekipmanın çok fazla bir şekilde } \\
\text { zarar, hasar görmesine sebep olan } \\
\text { hata türü }\end{array}$ & Yedi \\
\hline Yok & $\begin{array}{c}\text { Proje uygulamasında kargaşaya } \\
\text { neden olabilecek hata türü }\end{array}$ & Iki \\
\hline Orta & $\begin{array}{c}\text { Sistemin ya da projenin çalışmasını, } \\
\text { uygulanmasını etkileyen hata türü }\end{array}$ & Altı \\
\hline planlamalarda hafif hasarlara \\
nüşük
\end{tabular}

Burada sayılan etkenlerin değerlerini saptamada birden çok metot bulunmaktadır. Literatürde genellikle bu etkenlerin saptanmasında ve gösterilmesinde risk gösterge tabloları kullanılmaktadır. Bu anlatılan üç etken (Olasılık, şiddet ve saptanabilirlilik); projede ya da sistemde belirlenen her bir risk için hesaplanacak olan Risk öncelik (RÖS) sayısının hesaplanmasında kullanılmaktadır. (Liu et al. 2013; Su et al. 2012).

Çizelge 3. Risk Öncelik Sayısının Belirlenmesinde Saptanabilirlik (Keşfedilebilirlilik) (S) kademeleri (Akın 1998) 


\begin{tabular}{|c|c|c|}
\hline Keșfedilebilirlilik & Keşfedilebilirliliğin Olasılığı & Kademe \\
\hline $\begin{array}{l}\text { Fark Edilemeyen } \\
\text { Hata }\end{array}$ & $\begin{array}{l}\text { Riskin nedeninin ve takip eden } \\
\text { hatanın belirlenebilmesi mümkün } \\
\text { değil }\end{array}$ & On \\
\hline $\begin{array}{l}\text { Çok Az fark } \\
\text { edilen hata }\end{array}$ & $\begin{array}{l}\text { Riskin nedeninin belirlenebilmesi } \\
\text { mümkün değil çok uzak }\end{array}$ & Dokuz \\
\hline $\begin{array}{c}\text { Az fark } \\
\text { edilebilen hata }\end{array}$ & Riskin belirlenme nedeni uzak & Sekiz \\
\hline $\begin{array}{l}\text { Çok Düşük fark } \\
\text { edilebilen hata }\end{array}$ & $\begin{array}{l}\text { Riskin nedeninin belirlenebilmesi } \\
\text { çok düşük }\end{array}$ & Yedi \\
\hline $\begin{array}{c}\text { Düşük fark } \\
\text { edilebilen hata }\end{array}$ & $\begin{array}{l}\text { Riskin nedeninin belirlenebilmesi } \\
\text { düşük }\end{array}$ & Altı \\
\hline $\begin{array}{c}\text { Orta fark } \\
\text { edilebilen hata }\end{array}$ & $\begin{array}{l}\text { Potansiyel hatanın nedeninin } \\
\text { belirlenebilmesi orta }\end{array}$ & Beş \\
\hline $\begin{array}{l}\text { Yüksek Ortalama } \\
\text { fark edilebilen } \\
\text { hata }\end{array}$ & $\begin{array}{l}\text { Potansiyel hatanın nedeninin } \\
\text { belirlenebilmesi yüksek ortalama }\end{array}$ & Dört \\
\hline $\begin{array}{l}\text { Yüksek fark } \\
\text { edilebilen hata }\end{array}$ & $\begin{array}{l}\text { Potansiyel hatanın nedeninin } \\
\text { belirlenebilmesi yüksek }\end{array}$ & Üç \\
\hline $\begin{array}{l}\text { Çok Yüksek fark } \\
\text { edilebilen hata }\end{array}$ & $\begin{array}{l}\text { Potansiyel hatanın nedeninin } \\
\text { belirlenebilmesi çok yüksek }\end{array}$ & iki \\
\hline $\begin{array}{l}\text { Hemen hemen } \\
\text { kesin fark } \\
\text { edilebilen hata }\end{array}$ & $\begin{array}{l}\text { Potansiyel hatanın nedeninin } \\
\text { belirlenebilmesi hemen hemen } \\
\text { kesin }\end{array}$ & Bir \\
\hline
\end{tabular}

Bu hata ve risk analizinde; büyük risk öncelik sayısı olan risk ve hatadan başlamak suretiyle bu risk ve hataların uygun ekip ve yönetmeliklerle en aza indirilmesi ve önlemelerin alınması amaçlanmaktadır. Bununla birlikte bu risklerin gelecek zamanlarda da proje için tamamen ortadan kaldırılması hedeflenmektedir. Bu yöntem için risk öncelik sayıları; Hatanın oluşma Olasılığı (O), hatanın şiddeti ya da Ağırlığı (A) ve hatanın keşfedilebilirliliği ya da saptanması (S) değerlerinin çarpılması ile bulunmaktadır (Akın 1998; Wang et al. 2009; Xiao et al. 2011; Su et al. 2012). Çizelge 4 de RÖS özet çizelgesi verilmektedir.

RÖS=O(Hatanın oluşma olasılığı) *A(Hatanın şiddeti ya da ağırlığı) *S(Hatanın keşfedilebilirliliği ya da saptanması)

Bu risk belirleme metodunda kullanılan Risk öncelik sayısı, projelerdeki ve uygulamalardaki karşılaşılabilecek olan hata ve risklerin hangisinin öncelikle ve acil olarak ele alınması ve önemle üzerinde durulması gerektiğini belirlemede yardımcı bir faktör olmaktadır.

Çizelge 4. Risk Öncelik Sayısı (RÖS) Özet Çizelgesi (Akın 1998)

\begin{tabular}{cc}
\hline Risk Öncelik Sayısı (RÖS) & Önlem Vaziyeti \\
\hline RÖS<40 & Hafif Risk (Önleme gerek yok) \\
\hline $40 \leq$ RÖS $\leq 100$ & Orta risk (Önlem alınabilir) \\
\hline RÖS $>100$ & yüksek risk (Önlem alınmalıdır) \\
\hline
\end{tabular}

Ayrıca risk öncelik sayısı projeyi hatalardan ve risklerden arındırmak isteyen uzman ve araştırmacılara da önemli bir yol haritası çizmektedir. Çalışmada kullanılan bir diğer analiz metodu olan Pareto ise belirlenen risk ve hataların belli bir eşik değerine bağlı olarak risklerin öncelik durumlarını, yüzdelik oranlarını, önem derece ve sıralarını ortaya koymaktadır (Özcan 2001). Literatürde genelde (\%70-\%80) eşik oranları kullanılmakla birlikte hangi risklere daha fazla önem vermemiz ve hemen acil bir şekilde önlem almamız gerektiğini ortaya koymaktadır.

3. Bulgular: Rüzgâr Enerji Santrali Projelerinde Yapılan Topografik Yersel Ölçme ve Gözlemlerden Kaynaklanan Hata ve Risklerin HTEA ve Pareto Sistematiğinde İncelenmesi

Rüzgâr enerji santralleri projelerinde, projenin oturmuş olduğu arazinin, güncel ve hassas olarak harita, plan ve kesitlerde yansıtılması gerekmektedir. Bununla birlikte, projenin bulunduğu arazinin sayısal yükseklik modelinin oluşturulması ve bu arazi modelinin bilgisayar ortamında 3D (3 boyutlu) modellerinin yapılması da gerekli olmaktadır. Bununla birlikte, rüzgâr enerji projelerinin tasarımında, yine rüzgârın proje bölgesindeki esme yönüne ve projenin bulunduğu arazinin eğim yönüne göre simülasyonların yapılması da gerekli olmaktadır. Bu sayısal yükseklik modelinin Z (H yükseklik) koordinatlarına göre oluşturulması ve hatta $X, Y, Z$ (Konum) koordinatlarına bağlı olarak da güncel harita plan ve kesitlerin araziye yönelik çıkartılması için de sahada yapılacak olan mühendislik ya da topografik ölçümlerin hassas ve hatasız yapılması daha da önem arz etmektedir. Arazide yapılan bu ölçme 
konularında bazı hata ve risklerle karşılaşılabilmektedir. Çalışmada ilk olarak, konu ile ilgili uzman kişilerin de (Harita, inşaat, jeoloji, endüstri mühendisleri vb.) görüşleri gözetilerek, rüzgâr enerji santrali projelerindeki ölçme işlerine konu hangi hata ve risklerle karşılaşıldığı araştırılmakla birlikte 10 adet risk tespit edilmiştir. Buna göre belirlenen bu 10 risk HTEA sistematiğinde araştırılmıştır. Bu riskler arasında;

- Rüzgâr enerji santrali projesinin arazide yerleşeceği topografik bölgenin, yükseklik modelinde ve eğim bilgilerinde yapılan hata ve riskler, (Proses No:E1)

- Projede kullanılan ölçüm cihazlarının kalibrasyonlarının yapılmamasından kaynaklanan ölçüm hata ve riskleri, (Proses No:E2)

- Rüzgâr Enerjisi Proje sahasındaki yatay eksene ait ölçmeler için ( $X$ ve $Y$ koordinatlarının belirlenmesi) tasarımı yapılan ağdaki hata ve riskler, (Proses No:E3)

- Rüzgâr enerji projelerinin tesis edileceği bölgede heyelan kontrol analiz ve ölçümlerinin yapılmamasından kaynaklanan risk ve hatalar, (Proses No:E4)

- Rüzgâr enerji projesinin uygulanacağı arazinin jeolojik ve jeofiziksel test ve araştırmaların eksikliğinden kaynaklanan risk ve hatalar, (Proses No:E5)

- Rüzgâr enerji projeleri ile ilgili olarak yapılan aplikasyonların projesine uygun bir şekilde gerçekleştirilmemesinden kaynaklanan hata ve riskler, (Proses No:E6)

- Proje için yapılan yükseklik ölçmeleri (Z koordinatı) ve bu yükseklik ölçmeleri sonucu oluşturulan arazi kesit çizimlerinde yapılan hata ve riskler, (Proses No:E7)

- Rüzgâr enerji projesinin uygulanacağı arazide mülkiyet, kadastro ve kamulaştırma ile ilgili ölçmelerdeki yapılan hata ve riskler, (Proses No:E8)

- Proje ekibindeki ölçmeleri yapan ekiplerle ilgili organizasyon yönetim planlama ve kontrol konularında yapılan hata ve riskler, (Proses No:E9)

- Rüzgâr enerjisi projelerinin üretildiği koordinat sistemi ile arazi çalışma ve ölçümlerinin yapıldığı koordinat sistemi arasındaki uyuşumsuzluklardan doğan hataların deneyimsiz personeller tarafından yapılması sonucu oluşan hata ve riskler, (Proses No:E10)

gibi hata ve riskler tespit edilmiştir. Çalışmada ikinci olarak yine konu ile ilgili uzman kişilerin de görüşleri doğrultusunda bu risklerin oluşma olasılığı, riskin şiddeti ve riskin keşfedilebilirliliği birlikte değerlendirilerek Risk Öncelik Sayıları (RÖS) belirlenmiş ve riskin çizelge 4 de belirtilen hangi risk grubuna girdiği saptanmıştır. Bu risk ve hataların giderilebilmesi için de hangi önlemlerin alınması gerektiği araştırılmış ve sonuçta RÖS katsayıları tekrar değerlendirilmiştir. Bu önlemler alınırken ayrıca hangi yönetmeliklerden de yararlanılması gerektiği HTEA tablosunda belirtilmiştir. Önlemler alındıktan sonra bu risk ve hataların, risk grupları içinde hafif risk grubuna girdiği tespit edilmiştir (Çizelge 5). Çalışmada belirlenen bu risk ve hata gruplarının öncelik sıralarını belirlemek amacıyla 2 defa Pareto Analiz sistematiği kullanılmıştır. Bu sistematiğe göre her iki analiz türünde eşik değer olarak yaklaşık \%80 oranı seçilmiştir. Illk Pareto analizinde, HTEA tablosundaki belirlenen bütün risklerin, bu eşik değerine ve RÖS sayılarının kümülatif toplamına göre değerlendirmesi yapılmış buna göre rüzgar enerji santralleri projelerinde gerçekleştirilen ve topografik ya da mühendislik ölçmeleri sırasında oluşan E1, E5, E3, E7, E4, E6, E8 numaralı risk ve hataların ön plana çıktığı görülmüştür (Çizelge 6). İkinci Pareto analizinde ise yüksek risk ve hata oranına sahip olan risk ve hatalar, kendi içinde yaklaşık \%80 eşik değerine göre tekrar bir değerlendirmeye alınmış olup sonuçlar çizelge 7 de gösterilmektedir. Buna inceleme bulgusuna göre ise E1, E5, E3, E7, E4 numaralı risklerin en dikkat edilmesi gereken riskler olduğu anlaşılmaktadır. Uygulanan ilk Pareto analizi ve ikinci Pareto analizi ile ilgili grafiksel gösterimler Şekil 1 ve Şekil 2 de gösterilmektedir. 
Çizelge 5. Rüzgâr Enerji Santralleri Projelerinde Gerçekleştirilen Topografik ya da Mühendislik Ölçmeleri Sırasında Oluşan Risklerin HTEA Sistematiğinde İncelenmesi

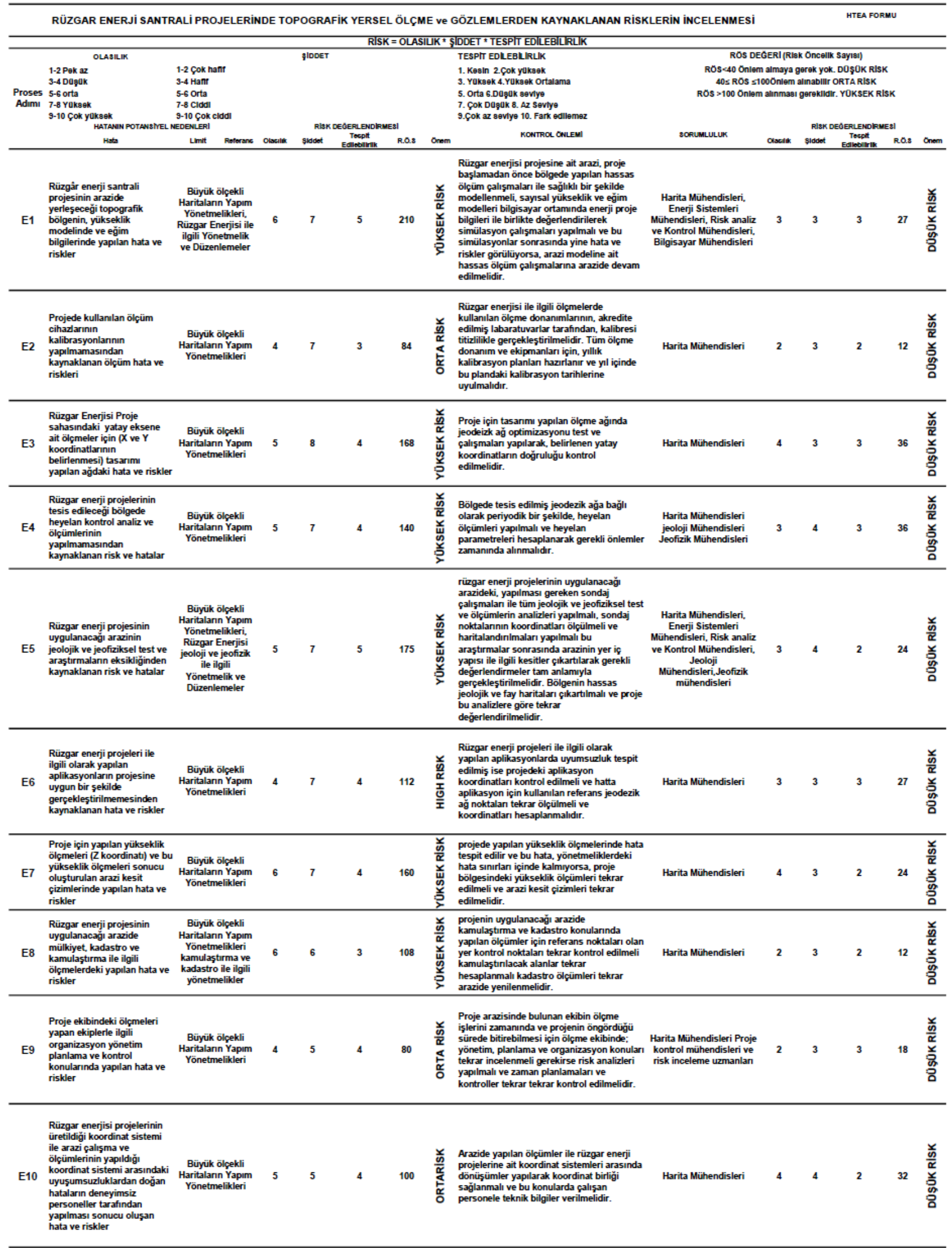


Çizelge 6. Rüzgâr Enerji Santralleri Projelerinde Gerçekleştirilen ve Topografik ya da Mühendislik Ölçmeleri Sırasında Oluşan Risklerin 1.Pareto Sistematiğinde İncelenmesi (\%80 Eşik Değerine Göre)

\begin{tabular}{|c|c|c|c|c|c|c|}
\hline \multicolumn{7}{|c|}{$\begin{array}{l}\text { RÜZGAR ENERJi SANTRALI PROJELERINDE TOPOGRAFIK YERSEL ÖLÇME Ve GÖZLEMLERDEN } \\
\text { KAYNAKLANAN RISKLERIN INCELENMESi }\end{array}$} \\
\hline SIRA NO & HATA ŞEKLi & PROSES NO & RÖS DEĞERI & RisK(\%) & KÜMÜLATIF RISK \% & RisK \\
\hline 1 & $\begin{array}{l}\text { Rüzgâr enerji santrali projesinin } \\
\text { arazide yerleşeceği topografik } \\
\text { bölgenin, yükseklik modelinde ve } \\
\text { eğim bilgilerinde yapılan hata ve } \\
\text { riskler }\end{array}$ & E1 & 210 & 15.71 & 15.71 & 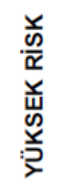 \\
\hline 2 & $\begin{array}{l}\text { Rüzgar enerji projesinin } \\
\text { uygulanacağı arazinin jeolojik ve } \\
\text { jeofiziksel test ve araştırmaların } \\
\text { eksikliğinden kaynaklanan risk ve } \\
\text { hatalar }\end{array}$ & E5 & 175 & 13.09 & 28.80 & 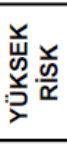 \\
\hline 3 & $\begin{array}{l}\text { Rüzgar Enerjisi Proje sahasındaki } \\
\text { yatay eksene ait ölçmeler için (X ve } \\
\text { Y koordinatlarının belirlenmesi) } \\
\text { tasarımı yapılan ağdaki hata ve } \\
\text { riskler }\end{array}$ & E3 & 168 & 12.57 & 41.36 & 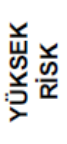 \\
\hline 4 & $\begin{array}{l}\text { Proje için yapılan yükseklik ölçmeleri } \\
\text { (Z koordinatı) ve bu yükseklik } \\
\text { ölçmeleri sonucu oluşturulan arazi } \\
\text { kesit çizimlerinde yapılan hata ve } \\
\text { riskler }\end{array}$ & E7 & 160 & 11.97 & 53.33 & 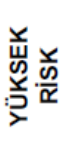 \\
\hline 5 & $\begin{array}{l}\text { Rüzgar enerji projelerinin tesis } \\
\text { edileceği bölgede heyelan kontrol } \\
\text { analiz ve ölçümlerinin } \\
\text { yapılmamasından kaynaklanan risk } \\
\text { ve hatalar }\end{array}$ & E4 & 140 & 10.47 & 63.80 & 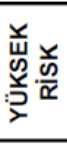 \\
\hline 6 & $\begin{array}{l}\text { Rüzgar enerji projeleri ile ilgili olarak } \\
\text { yapılan aplikasyonların projesine } \\
\text { uygun bir şekilde } \\
\text { gerçekleştirilmemesinden } \\
\text { kaynaklanan hata ve riskler }\end{array}$ & E6 & 112 & 8.38 & 72.18 & 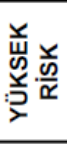 \\
\hline 7 & $\begin{array}{l}\text { Rüzgar enerji projesinin } \\
\text { uygulanacağı arazide mülkiyet, } \\
\text { kadastro ve kamulaştırma ile ilgili } \\
\text { ölçmelerdeki yapılan hata ve riskler }\end{array}$ & E8 & 108 & 8.08 & 80.25 & 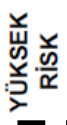 \\
\hline 8 & $\begin{array}{l}\text { Rüzgar enerjisi projelerinin üretildiği } \\
\text { koordinat sistemi ile arazi çalışma ve } \\
\text { ölçümlerinin yapıldığı koordinat } \\
\text { sistemi arasındaki } \\
\text { uyuşumsuzluklardan doğan hataların } \\
\text { deneyimsiz personeller tarafından } \\
\text { yapııması sonucu oluşan hata ve } \\
\text { riskler }\end{array}$ & E10 & 100 & 7.48 & 87.73 & 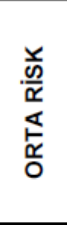 \\
\hline 9 & $\begin{array}{l}\text { Projede kullanılan ölçüm cihazlarının } \\
\text { kalibrasyonlarının yapıımamasından } \\
\text { kaynaklanan ölçüm hata ve riskleri }\end{array}$ & E2 & 84 & 6.28 & 94.02 & $\underset{\frac{\sigma}{\alpha}}{\stackrel{\underline{\phi}}{\alpha}}$ \\
\hline 10 & $\begin{array}{l}\text { Proje ekibindeki ölçmeleri yapan } \\
\text { ekiplerle ilgili organizasyon yönetim } \\
\text { planlama ve kontrol konularında } \\
\text { yapılan hata ve riskler }\end{array}$ & E9 & 80 & 5.98 & 100.00 & 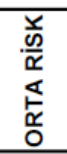 \\
\hline
\end{tabular}

Şekil 1. Rüzgâr Enerji Santralleri Projelerinde Gerçekleştirilen ve Topografik ya da Mühendislik Ölçmelerinde Oluşan Risklerin 1. Pareto Analizindeki Grafik Gösterimi (\%80 Eşik Değerine Göre)

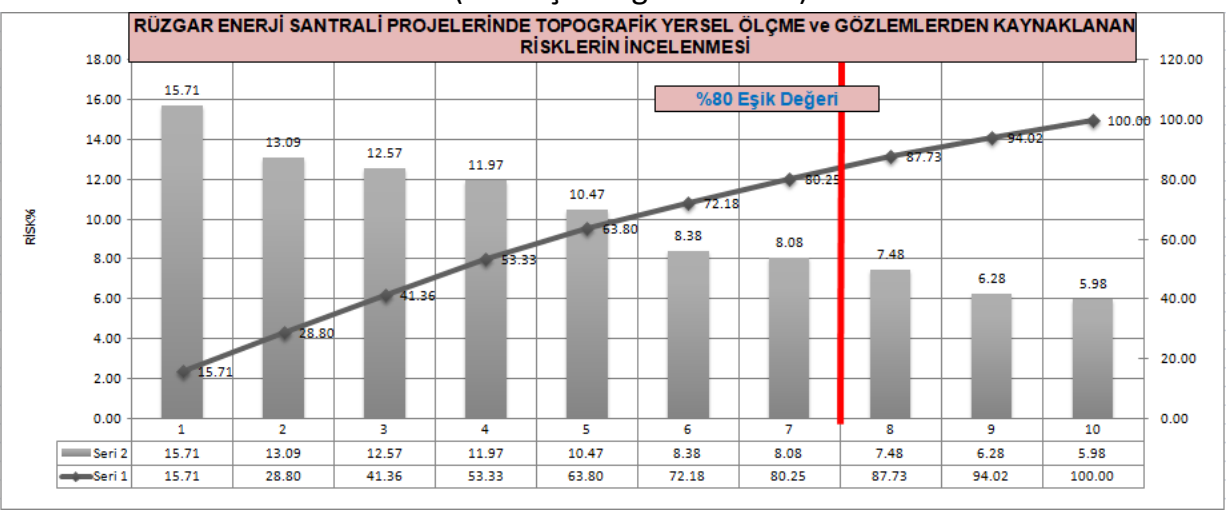


Çizelge 7. Rüzgâr Enerji Santralleri Projelerinde Gerçekleştirilen ve Topografik ya da Mühendislik Ölçmelerinde Oluşan Risklerin 2.Pareto Sistematiğinde İncelenmesi (\%80 Eşik Değerine Göre)

\begin{tabular}{|c|c|c|c|c|c|c|}
\hline \multicolumn{7}{|c|}{$\begin{array}{l}\text { RÜZGAR ENERJi SANTRALI PROJELERINDE TOPOGRAFiK YERSEL ÖLCCME ve GÖZLEMLERDEN } \\
\text { KAYNAKLANAN RiSKLERIN INCELENMESi (YÜKSEK RISKLERIN KENDi ARASINDA) }\end{array}$} \\
\hline SIRANO & HATA ŞEKLI & PROSES NO & RÖS DEĞERI & RisK(\%) & KÜMÜLATiF RISK \% & Risk \\
\hline 1 & $\begin{array}{l}\text { Rüzgâr enerji santrali projesinin } \\
\text { arazide yerleşeceği topografik } \\
\text { bölgenin, yükseklik modelinde ve } \\
\text { eğim bilgilerinde yapılan hata ve } \\
\text { riskler }\end{array}$ & E1 & 210 & 19.57 & 19.57 & 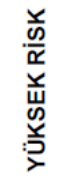 \\
\hline 2 & $\begin{array}{l}\text { Rüzgar enerji projesinin } \\
\text { uygulanacağı arazinin jeolojik ve } \\
\text { jeofiziksel test ve araştırmaların } \\
\text { eksikliğinden kaynaklanan risk ve } \\
\text { hatalar }\end{array}$ & E5 & 175 & 16.31 & 35.88 & 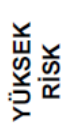 \\
\hline 3 & $\begin{array}{l}\text { Rüzgar Enerjisi Proje sahasındaki } \\
\text { yatay eksene ait ölçmeler için ( } X \text { ve } \\
\text { Y koordinatlarının belirlenmesi) } \\
\text { tasarımı yapılan ağdaki hata ve } \\
\text { riskler }\end{array}$ & E3 & 168 & 15.66 & 51.54 & 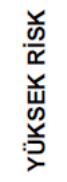 \\
\hline 4 & $\begin{array}{l}\text { Proje için yapılan yükseklik } \\
\text { ölçmeleri (Z koordinatı) ve bu } \\
\text { yükseklik ölçmeleri sonucu } \\
\text { oluşturulan arazi kesit çizimlerinde } \\
\text { yapılan hata ve riskler }\end{array}$ & E7 & 160 & 14.91 & 66.45 & 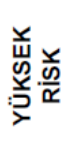 \\
\hline 5 & $\begin{array}{l}\text { Rüzgar enerji projelerinin tesis } \\
\text { edileceği bölgede heyelan kontrol } \\
\text { analiz ve ölçümlerinin } \\
\text { yapılmamasından kaynaklanan risk } \\
\text { ve hatalar }\end{array}$ & E4 & 140 & 13.05 & 79.50 & 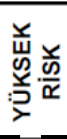 \\
\hline 6 & $\begin{array}{l}\text { Rüzgar enerji projeleri ile ilgili } \\
\text { olarak yapılan aplikasyonların } \\
\text { projesine uygun bir şekilde } \\
\text { gerçekleştirilmemesinden } \\
\text { kaynaklanan hata ve riskler }\end{array}$ & E6 & 112 & 10.44 & 89.93 & 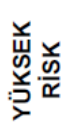 \\
\hline 7 & $\begin{array}{l}\text { Rüzgar enerji projesinin } \\
\text { uygulanacağı arazide } \\
\text { mülkiyet,kadastro ve kamulaştırma } \\
\text { ile ilgili ölçmelerdeki yapılan hata } \\
\text { ve riskler }\end{array}$ & E8 & 108 & 10.07 & 100.00 & 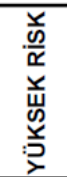 \\
\hline
\end{tabular}

Şekil 2. Rüzgâr Enerji Santralleri Projelerinde Gerçekleştirilen ve Topografik ya da Mühendislik Ölçmelerinde Oluşan Risklerin 2. Pareto Analizindeki Grafik Gösterimi (\%80 Eşik Değerine Göre)

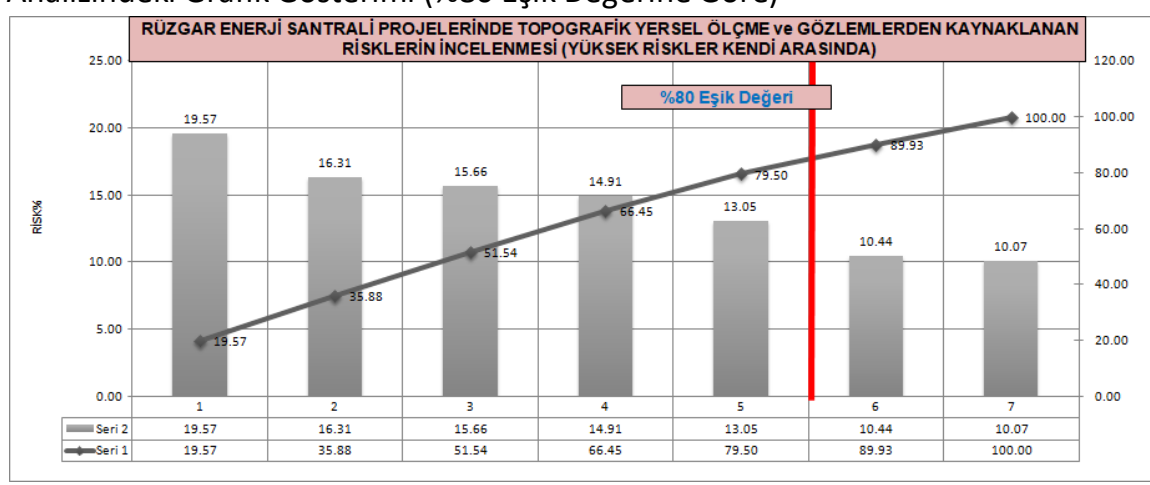

\section{Sonuçlar}

Rüzgâr enerji santrali projelerinde, arazinin konum ve geometrisinin belirlenip altlık olarak kullanılacak ve projeye temel teşkil edecek güncel plan ve haritaların oluşturulması gerekmektedir.
$\mathrm{Bu}$ haritaların oluşturulmasında sahada gerçekleştirilen mühendislik ölçmelerinin payı oldukça büyük olmaktadır. Yapılan ölçümler arazide tesis edilen hassas jeodezik ağa göre yapılmadığında çeşitli risk ve hatalar oluşabilmektedir. Çalışmada rüzgar enerji projeleri için böylesine önemli olan topografik 
ölçme faaliyetlerinin gerçekleştirilmesi sırasında bazı hata ve riskler oluşuyor ise bu hata ve risklerin HTEA ve 1.Pareto sistematiğinde araştırılmıştır. Ayrıca oluşan riskler hakkında alınması gereken tedbirler ilgili uzman ekiplerin görüşü de dikkate alınarak belirtilmektedir. Bu sistematik inceleme ve araştırma sonrasında, yüksek risk grubunda yer alan bu hatalar, kendi içinde \%80 eşik değerine bağlı olarak 2. Pareto analizine göre tekrar incelendiğinde ise ilk 5 risk ve hatanın, rüzgâr santrali projeleri ile ilgili ölçmelerinin yapılması sırasında daha fazla dikkate alınması ve önlemlerinin hemen alınması gerektiği ortaya çıkmıştır.

Çalışmada, bu tür enerji santrali ile ilgili olan projelerde, yersel topografik ölçme gözlemleri yapan araştırmacı, uzman ve mühendislere bu gözlemler ve ölçmeler konusunda oluşabilmesi muhtemel hata ve risklerin neler olduğu gösterilmeye çalışılmıştır. Ayrıca, yine bu çalışmada hata türü etkileri analizi ile pareto analizinin konu ile ilgili yönetmelikler ve uzman görüşleri de dikkate alınarak, bu tür hataların oluşmadan önce önüne geçilmesi ve büyük maddi kayıpların bu tür projelerde önlenmesi açısından, etkin birer metot olduğu gösterilmek istenmiş ve araştırılmıştır.

\section{Kaynaklar}

Ajayi, 0.0.,2009. Assessment of utilization of wind energy resources in Nigeria. Energy Policy, (37) (2009), 750-753, https://doi.org/10.1016/j.enpol.2008.10.020

Akın, B., 1998. ISO 9000 Uygulamasında ve İşletmelerde Hata Türü ve Etkileri Analizi. Bilim Teknik Yayınevi, İstanbul, 182.

Amoo, O.M., 2012. Evaluation of the wind energy potential of two south west sites in Nigeria. Frontiers in Energy, 6(3), 237-246, https://doi.org/10.1007/s11708-012-0201-2

Argin, M., Yerci, V., Erdogan, N., Kucuksari, S., Cali, U., 2019. Exploring the offshore wind energy potential of Turkey based on multicriteria site selection.
Energy Strategy Reviews, 23 (2019), 33-46, https://doi.org/10.1016/j.esr.2018.12.005

Beccali, M., Cirrincione, G., Marvuglia, A., Serporta, C., 2010. Estimation of wind velocity over a complex terrain using the Generalized Mapping Regressor. Applied Energy, (87)(2010), 884-893, https://doi.org/10.1016/j.apenergy.2009.05.026

Bosch J, Staffell I, Hawkes, AD (2018) Temporally explicit and spatially resolved global offshore wind energy potentials. Energy, 163 (2018), 766-781, https://doi.org/10.1016/j.energy.2018.08.153

Brouwer, S.R., Al-Jibouri, S.H.S., Cárdenas, I.C., Halman, J.I.M. (2018). Towards analysing risks to public safety from wind turbines. Reliability Engineering and System Safety, 180 (2018), 77-87, https://doi.org/10.1016/j.ress.2018.07.010

Cellura, M., Cirrincione, G., Marvuglia, A., Miraoui, A., 2008. Wind speed spatial estimation for energy planning in Sicily: A neural kriging application. Renewable Energy, (33)(2008), 1251-1266, https://doi.org/10.1016/j.renene.2007.08.013

Chin, K.S., Wang, Y.M., Poon Gary Ka, K., Yang, J.B., 2009. Failure mode and effects analysis using a group-based evidential reasoning approach. Computers \& Operations Research, 36(2009):17681779, https://doi.org/10.1016/j.cor.2008.05.002

Finardi, S., Tinarelli, G., Faggian, P., Brusasca, G., 1998. Evaluation of different wind field modeling techniques for wind energy applications over complex topography. Journal of Wind Engineering and Industrial Aerodynamics, 74-76 (1998), 283294, $\quad$ https://doi.org/10.1016/S01676105(98)00025-7

Ferragut, L., Montenegro, R., Montero, G., Rodri'guez, E., Asensio, M.I., Escobar, J.M., 2010. Comparison between 2.5-D and 3-D realistic models for wind field adjustment. Journal of Wind Engineering and Industrial Aerodynamics, 98 (2010), 548-558, https://doi.org/10.1016/j.jweia.2010.04.004

Fang, J., Peringer, A., Stupariu, M.S., Patru-Stupariu, I., Buttler, A., Golay, F., Porté-Agel, F., 2018. Shifts in wind energy potential following land-use driven vegetation dynamics in complex terrain. Science of 
the Total Environment, 639 (2018), 374-384, https://doi.org/10.1016/j.scitotenv.2018.05.083

Gualtieri, G., 2019. A comprehensive review on wind resource extrapolation models applied in wind energy. Renewable and Sustainable Energy Reviews, 102(2019),

215-233,

https://doi.org/10.1016/j.rser.2018.12.015

Han, X., Liu, D., Xu, C., Shen, W.Z., 2018. Atmospheric stability and topography effects on wind turbine performance and wake properties in complex terrain. Renewable Energy, 126 (2018), 640-651, https://doi.org/10.1016/j.renene.2018.03.048

Kang, J., Sun, L., Sun, H., Wu, C., 2017. Risk assessment of floating offshore wind turbine based on correlation-FMEA. Ocean Engineering, 129 (2017), 382-388, https://doi.org/10.1016/j.oceaneng.2016.11.048

Kang, J., Sun, L., Guedes Soares, C., 2019. Fault Tree Analysis of floating offshore wind turbines. Renewable Energy, 133(2019), 1455-1467, https://doi.org/10.1016/j.renene.2018.08.097

Kim, Y.H., Lim, H.C., 2017. Effect of island topography and surface roughness on the estimation of annual energy production of offshore wind farms. Renewable Energy, 103 (2017), 106-114, https://doi.org/10.1016/j.renene.2016.11.020

Kucukali, S., 2016. Risk scorecard concept in wind energy projects: An integrated approach. Renewable and Sustainable Energy Reviews, 56(2016), 975-987, https://doi.org/10.1016/j.rser.2015.12.017

Leimeister, M., Kolios, A., 2018. A review of reliabilitybased methods for risk analysis and their application in the offshore wind industry. Renewable and Sustainable Energy Reviews, 91 (2018), 1065-1076, https://doi.org/10.1016/j.rser.2018.04.004

Li, J., Yu, X(B)., 2017. LiDAR technology for wind energy potential assessment: Demonstration and validation at a site around Lake Erie. Energy Conversion and Management, 144 (2017), 252-261, https://doi.org/10.1016/j.enconman.2017.04.061
Liu, H.C., Liu, L., Liu, N., 2013. Risk Evaluation Approaches in Failure Mode and Effects Analysis: A Literature Review. Expert Systems with Applications, 40(2013), 828-838, https://doi.org/10.1016/j.eswa.2012.08.010

Liua, F., Sun, F., Liu, W., Wang, T., Wang, H., Wang, X., Lim, W.H., 2019. On wind speed pattern and energy potential in China. Applied Energy, 236 (2019), 867876, https://doi.org/10.1016/j.apenergy.2018.12.056

Lun, Y.F., Mochida, A., Yoshino, H., Murakami, S., 2007. Applicability of linear type revised $k$ - e models to flow over topographic features. Journal of Wind Engineering and Industrial Aerodynamics, 95(2007), 371-384, https://doi.org/10.1016/j.jweia.2006.09.004

Marugána, A.P., Márquez, F.P.G., Perez, J.M.P., RuizHernández, D., 2018. A survey of artificial neural network in wind energy systems. Applied Energy, 228(2018), $1822-1836$ https://doi.org/10.1016/j.apenergy.2018.07.084

Miryousefi Aval S.M., Ahadi, A., Hayati, H., 2016. A novel method for reliability and risk evaluation of wind energy conversion systems considering wind speed correlation. Frontiers in Energy, 10(1), 46-56, https://doi.org/10.1007/s11708-015-0384-4

Nedjari, H.D., Guerri, O., Saighi, M., 2017. CFD wind turbines wake assessment in complex topography. Energy Conversion and Management, 138 (2017), 224-236, https://doi.org/10.1016/j.enconman.2017.01.070

Özcan, S., 2001. İstatiksel Proses Kontrol Tekniklerinden Pareto Analizi ve Çimento Sanayiinde Bir Uygulama. Cumhuriyet Universitesi, Iktisadi ve Idari Bilimler Dergisi, 2(2), 151-174,

Ramachandra, T.V., Shruthi, B.V., 2005. Wind Energy Potential Mapping in Karnataka, India, using GIS. Energy Conversion and Management, (46)(2005), 1561-1578, https://doi.org/10.1016/j.enconman.2004.07.009

Rolik, Y., 2017. Risk Management in Implementing Wind Energy Project. Procedia Engineering, 178(2017), $278 \quad$ 288, https://doi.org/10.1016/j.proeng.2017.01.115 
Shafiee, M., Dinmohammadi, F., 2014. An FMEA-Based Risk Assessment Approach for Wind Turbine Systems: A Comparative Study of Onshore and Offshore. $\quad$ 7(2), 619-642, https://doi.org/10.3390/en7020619

Shu, Z.R., Li, Q.S., He, Y.C., Chan, P.W., 2016. Observations of offshore wind characteristics by Doppler-LiDAR for wind energy applications. Applied Energy, 169(2016), 150-163, https://doi.org/10.1016/j.apenergy.2016.01.135

Su, X., Deng, Y., Mahadevan, S., Bao, Q., 2012. An Improved Method For Risk Evaluation in Failure Modes and Effects Analysis of Aircraft Engine Rotor Blades. Engineering Failure Analysis, 26(2012), 164174 ,

https://doi.org/10.1016/j.engfailanal.2012.07.009

Şen, Z., 1999. Terrain Topography Classification for Wind Energy Generation. Renewable Energy, (16)(1999), 904-907, https://doi.org/10.1016/S0960-1481(98)00304-8

Tarawneh, Q.Y., Şahin, A.D., 2003. Regional wind energy assessment technique with applications. Energy Conversion and Management, (44)(2003), 1563-1574, https://doi.org/10.1016/S01968904(02)00164-4
Tazi, N., Châtelet, E., Bouzidi, Y., 2017. Using a Hybrid Cost-FMEA Analysis for Wind Turbine Reliability Analysis. Energies, 10(3), 276, https://doi.org/10.3390/en10030276

Wang, Y.M., Chin, K.S., Poon Gary Ka, K., Yang, J.B., 2009. Risk Evaluation in Failure Mode and Effects Analysis Using Fuzzy Weighted Geometric Mean. Expert Systems with Applications, 36(2009), 11951207, https://doi.org/10.1016/j.eswa.2007.11.028

Xiao, N., Huang, H.Z., Li, Y., He, L., Jin, T., 2011. Multiple Failure Modes Analysis And Weighted Risk Priority Number Evaluation in FMEA. Engineering Failure Analysis, 18(2011), 1162-1170, https://doi.org/10.1016/j.engfailanal.2011.02.004

Xinyao, J., Yongjun, H., Fuchao, L., 2017. Research on the evaluation of wind power projects of investment risk. Procedia Computer Science, 111(2017), 388-398, https://doi.org/10.1016/j.procs.2017.06.039

Yssaad, B., Abene, A., 2015. Rational Reliability Centered Maintenance Optimization for power distribution systems. Electrical Power and Energy Systems, 73(2015), 350-360, https://doi.org/10.1016/j.ijepes.2015.05.015 